\title{
The Acoustical Characteristics of the Kocatepe Mosque in Ankara, Turkey
}

\author{
Zühre Sï̈ and Semiha Yilmazer ${ }^{* \dagger}$
}

\begin{abstract}
* Program in Architectural Acoustics, School of Architecture, Rensselaer Polytechnic Institute, Troy, NY 12180, USA
** Department of Interior Architecture and Environmental Design, Bilkent University, 06800 Bilkent, Ankara, Turkey † Corresponding author: Tel: 900312290 2592; Fax: 900312266 4136; E-mail: semiha@bilkent.edu.tr
\end{abstract}

Received 5 October 2006; accepted 5 September 2007

\begin{abstract}
This research investigates the acoustical characteristics of mosques of the classical Ottoman period and the contemporary period. Kocatepe Mosque, the major mosque in Ankara, Turkey, as a case from the contemporary era is a unique combination of $16^{\text {th }}$ century Ottoman aesthetics and $20^{\text {th }}$ century technology. Although previous and recent mosques have been inspired by this combination, the use of a reinforced concrete dome without cavity resonators could cause long reverberation times especially in low frequencies. The purpose of this study was to investigate this condition by studying Kocatepe Mosque. The acoustical characteristics of the mosque were analyzed by computer simulation. Objective room-acoustic indicators including reverberation time (RT), early decay time (EDT), clarity (C80), definition (D50), lateral fraction (LF), speech transmission index (STI) and strength (G) are presented. The results show that the acoustical quality of Kocatepe Mosque is not optimal when it is empty, and closest to optimal conditions when fully occupied. The new techniques to overcome excessive low frequency attenuation caused by huge concrete shells of today's mosques are discussed in conclusion.
\end{abstract}

Keywords: Acoustical parameters, Mosque acoustics, ODEON, Reverberation time, Room acoustics, Speech intelligibility

\section{Introduction}

The mosque as an important building type of Muslim architecture has evolved to meet Islamic needs. A variety of different worship activities happen within these multifunctional public spaces; these different uses have different acoustical requirements. As in many other religions, worshippers sometimes need solitude while at other times they want to feel in absolute unity with the others present. Acoustics are one of the basic means of creating different effects (Karabiber, 1999). Although mosques are uniquely important buildings in every Muslim community, their acoustical quality has not received adequate attention especially in recent examples.

The architect Sinan's mosques have been studied in a European Commission Fifth Framework INCO-MED Program called "Conservation of the Acoustical Heritage by Revival and Identification of Sinan's Mosques' Acoustics (CAHRISMA)"; this study generally proved them to be very efficient (Yuksel, Binan \& Unver, 2003). The CAHRISMA project, completed in 2003, studied the acoustics of old Byzantine churches and mosques built by the $16^{\text {th }}$ century Turkish Architect Sinan. Another priority was to introduce the concept of Hybrid Architectural Heritage; the idea is that, the architectural heritage concept considered in conservation and restoration projects, should be upgraded to cover acoustical as well as visual aspects for spaces having acoustic importance (CAHRISMA, 2007; Karabiber, 2000).

Studies have compared the acoustical quality of various spaces. One study by Fausti, Pompoli and Prodi (2003) compared the acoustics of mosques and churches. They found that reverberation time, in the unoccupied condition, is very long, giving them a unique feeling of majesty. In another study, Karabiber and Erdogan (2002) compared the ancient mosque of Kadırga Sokullu Mehmet Pasa with a recent one, Sisli Merkez. They concluded that although there was no great difference between the total sound absorption of the spaces, the acoustics in the ancient mosque was better.

Sinan's important mosques have been analyzed in other studies besides the CAHRISMA project (Kayili, 2002; Topaktas, 2003). Kayili (2000) argued that the acoustic systems Sinan applied, especially using Helmholtz (cavity) resonators technology, are among the most successful applications of acoustic science. It is believed that this application became a tradition in Ottoman mosques. However, it has not been possible to investigate the state of resonators in every mosque dome as such an opportunity only occurs during restoration work; however, that opportunity did arise in the Sultan Ahmet (Blue) Mosque. Naturally, when the openings of the resonators are completely closed they are unable to function. 
In large spaces, and at low frequencies, this causes undesirable reverberation curves. This was confirmed by measurements of reverberation time in the Suleymaniye and Selimiye Mosques where a long reverberation time was measured, especially in the low frequencies (Kayili, 2005). However, the recent mosques, which have domes built up with reinforced concrete without cavity resonators, have not been studied.

In this study, the Kocatepe Mosque was chosen as an example of the Ottoman style concrete domed mosques to investigate this specific condition and its outcome in mosque acoustics, also to contribute to the ongoing research on hybrid architectural heritage. The Kocatepe Mosque, with its architectural grandeur and congregation capacity, has a considerable social role within the community it serves. It is also one of the leading examples of the contemporary era of reinforced concrete dome typology in mosque acoustics and architecture. The main difference between the recent mosques, with their new technology and the Ottoman era Sinan mosques, are the cavity resonators that were frequently used in ancient domes to balance low frequency reverberation. The effects of this missing architectural element in recent mosques, such as the Kocatepe Mosque, are discussed in acoustical terms.

The acoustical quality of the mosques has also been discussed in the literature (Abdou, 2003; Karabiber, 1999; Kayili, 2002; Prodi \& Marsilio, 2003; Utami, 2005). Mosque design is mainly influenced by worship considerations; three distinct activities are carried out in a mosque, either separately or together. One is prayers, either individually or in a group led by a leader, the Imam. The second is attendance at a sermon being delivered on its own or within the Friday noon prayers. The third is listening to or reciting some verses from the Holy Quran. All these activities require a high level of speech audibility and intelligibility. To ensure good listening conditions acoustical needs must be considered in the design phase (Abdou, 2003).

In summary, there are three distinct acoustical requirements for mosques:

- Audibility of the namaz (prayer) orders of the Imam (prayer leader)

- Recognizable sermon of the preacher
- Listening to or joining in the recital of the musical versions of the Holy Quran

Thus, intelligibility of both speech and other sounds is extremely important, especially important for holy tones that must be both spacious and effective (Hamadah \& Hamouda, 1998; Karabiber, 1999). Several acoustical parameters govern speech audibility, intelligibility and spaciousness of sound; the parameters usually employed in the acoustical analysis of mosques are reverberation time, sound pressure level distribution and sound transmission index (Suarez, Sendra, Navarro \& Leon, 2004). In order to clarify of the manner, the purpose of this study is also to evaluate and predict the acoustical quality of the Kocatepe Mosque by assesing these parameters as major variables.

\section{Kocatepe Mosque}

\section{History}

The idea of building the Kocatepe Mosque dates back to a project competition in 1940 . The winner at this stage was a joint project by Vedat Dalokay and Nejat Tekelioğlu. The complex was to consist of a mosque for two thousand people, the main offices of the Presidency of Religious Affairs, a high Islamic institute, a library, an auditorium, a museum, a parking lot for two hundred cars, retail shops, a large kitchen, and a polyclinic. A second competition was held in 1957 and the part of the project containing the main offices of the Presidency of Religious Affairs was finished in 1964. A third competition in 1967 was won by Hüsrev Tayla and Fatih Uluengin. The Kocatepe Mosque was inaugurated in 1987 with a capacity for a congregation of 15.000 (Türkiye Diyanet Vakfi [Presidency of Religious Affairs], 2007).

\section{Architectural Features}

Commanding the hill of Kocatepe, the mosque is a modern city landmark. Its architecture combines the traditional Ottoman style of the $16^{\text {th }}$ century with $20^{\text {th }}$ century technology (see Figure 1). With its four minarets, the mosque resembles Selimiye; its central dome and half domes are inspired by the Sultan Ahmet Mosque of Mehmet Aga, from the school of Sinan the Architect.
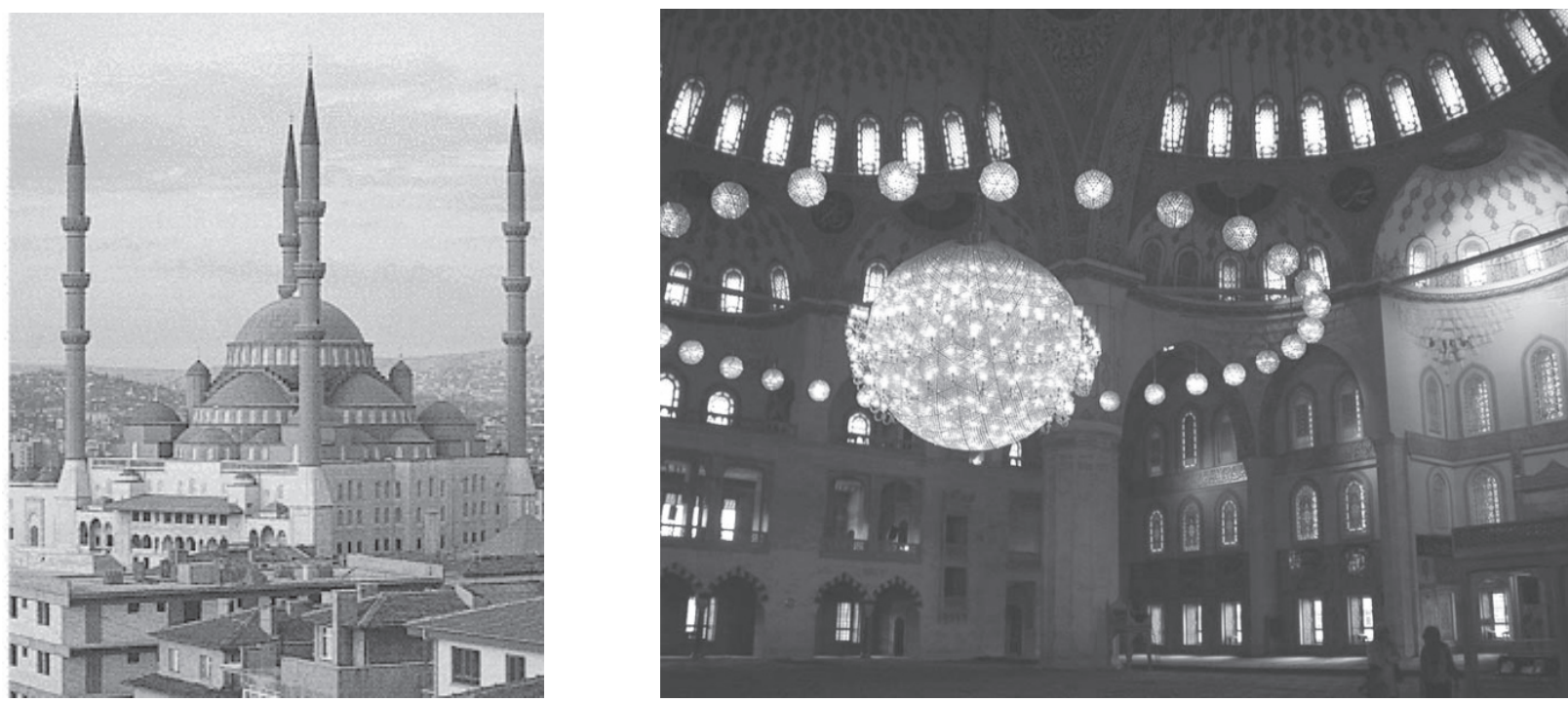

Figure 1: Exterior and interior views of the Kocatepe Mosque, Ankara (Türkiye Diyanet Vakfi, 2007). 
The main mosque has an estimated volume of $68,696 \mathrm{~m}^{3}$ and a floor area of $4,288 \mathrm{~m}^{2}$. It is $64 \times 67 \mathrm{~m}$, with a height of $48.5 \mathrm{~m}$; the dome has a diameter of $25.5 \mathrm{~m}$. There are four smaller half domes surrounding the central dome. These half domes are enlarged with 12 domes. The main dome rests on four large pillars (elephant feet) each with a diameter of 3 meters. Unlike earlier mosques, the elephant feet are only 3 meters in diameter because of modern technology. The interior of the mosque is thus more spacious and there is less visual and auditory distraction than with larger columns. The main part of the mosque (harem) is surrounded by galleries in a "U" form. The galleries have two stories, quite unlike the classical Istanbul mosques. As a result, more space is added to the harem.

The mosque as a whole is built on a reinforced concrete framework system and the outsides are covered with artificial stone. The dome, the half domes and the minarets are concrete. All the domes are covered with traditional lead. The points of the cupolas surrounding the courtyard and the ones over the side doors are of marble. The points of the main dome, the ones surrounding it and the minarets are made of gold plated copper. In the interior classical Ottoman decoration dominates with marble and gold leaf, stained-glass windows and decorative tiles. The writings on the main dome, the lion chest writings, and the writings circling the dome like a belt are of gold plated brass. One main door and four side doors are made of nailed wood, without nails. The sides of the staircases are covered with marble. Small balconies are built at the same level as the landings, allowing more space for landings. The niche with a height of 10 meters and the pulpit with a height of 8.70 meters are both marble decorated with special ornaments.

The stained glass panes that create a significant effect in the interior decoration of the mosque are made of special glass and represent a transition from classical Ottoman style to modern style. The inner area of the mosque is lit by one main chandelier, 32 satellite chandeliers and 4 corner chandeliers. The main chandelier is 5.5 meters in diameter; its chains are made of crystal balls and the frames are gold plated. There is a central heating system providing heat from the floor. The Harem has a hand-woven carpet of a particular type with the same pattern seen in the Afyon Ulu Mosque. The galleries also have carpets that are machine-woven with special patterns (Türkiye Diyanet Vakfı [Presidency of Religious Affairs], 2007).

\section{Research Method}

Technological developments provide new opportunities for acoustical design. The acoustical assessment of a space in the design phase used to be done with scale models that are timeconsuming and unpractical. It is now possible to use computer simulation to analyze acoustical properties prior to the actual construction of a building and acoustical design can become an integral part of the architectural design process. Computer simulation has proven to be a viable tool in designing music buildings such as concert halls, opera houses, and multi- purpose auditoria. These not only minimize unexpected acoustic problems but they also allow many alternatives to be tested in a short time span (Schmidt \& Kirkegaard, 2004).

Computer simulations of the Kocatepe Mosque were carried out using ODEON Room Acoustics Program 6.05 software, which was released by the Technical University of Denmark (Naylor, 1993). The calculation method of this software is based on prediction algorithms including the image-source method and ray tracing. The ODEON Room Acoustics Program also takes into account the statistical properties of the room's geometry and absorption (Rindel, 2000).

In 2001, as a part of the CAHRISMA project, three Byzantine churches and three mosques were modeled in the Odeon room acoustic program (Weitze, Christensen, Rindel \& Gade, 2001). These geometries are dominated by spherical and cylindrical (concave/convex) shapes, with large domes dominating the ceiling. Another feature is numerous columns and galleries that obstruct the direct sound. In the models, changes can be made in calculation parameters such as the transition order (TO), the number of rays and the number of subdivision into plane surfaces of concave/convex surfaces. This is done to investigate the effect of the acoustic parameters in different rooms (according to ISO 3382). This study shows that the ray tracing method yields the best results $(\mathrm{TO}=0$ for complex rooms with many curved surfaces, modeled with relatively small plane surfaces.

In this study, a 3D Model of the Kocatepe Mosque is obtained using CAD Software. The model is imported to the ODEON Room Acoustics Program. Figure 2 shows the 3D display of the model.

Two omni-directional point sources and a receiver are specified for each activity pattern. Figures 3 and 4 illustrate the locations of the receiver and the sources. Source 1 indicates the mihrab and Source 2 indicates the minbar. Which is activated depends on the activity.
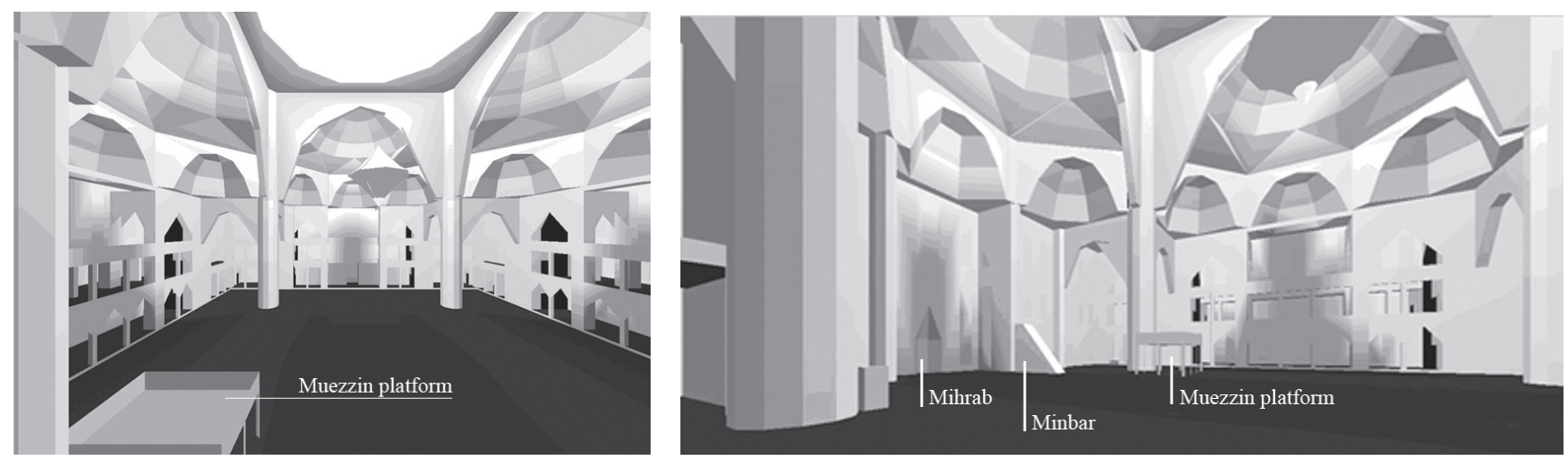

Figure 2: 3D display of the mosque. 

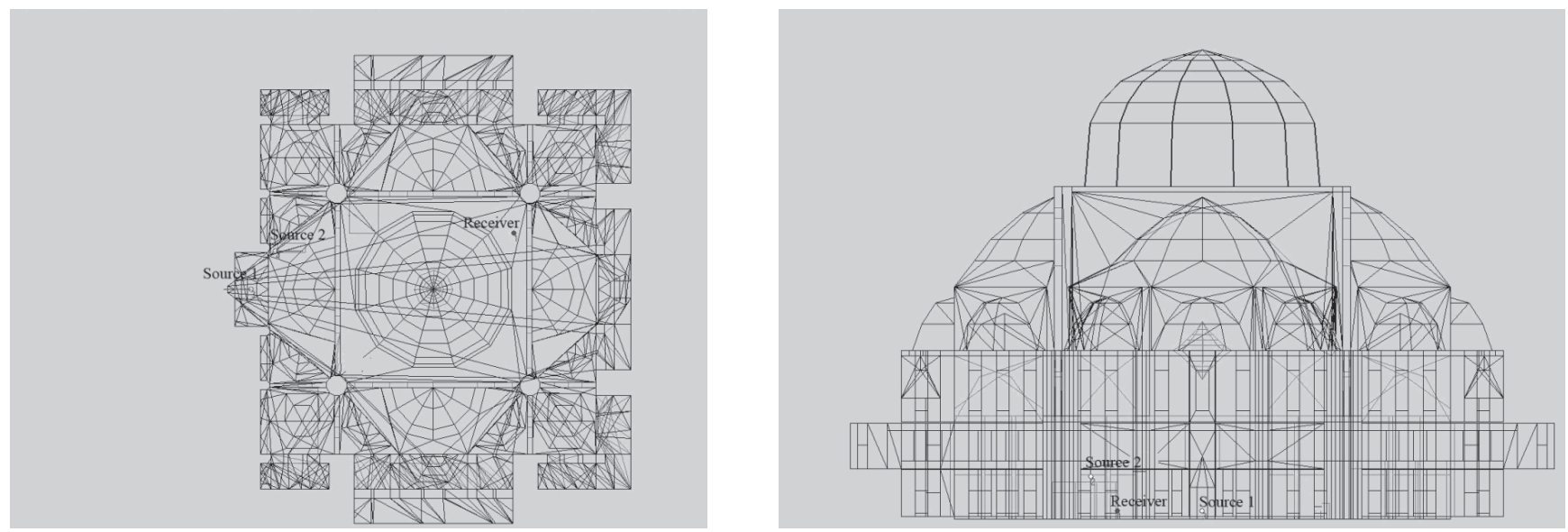

Figure 3: Plan and elevation view of the source and receiver locations.

Different materials at different sections of the mosque with different sound absorption coefficients are assigned (Table 1). After fixing the calculation parameters, the selected receiver surfaces are divided into grids assigning $0.96 \mathrm{~m}^{2}$ for each person praying (Abdou, 2003). In order to get the results of different acoustical parameters and their distribution throughout the mosque, the maps and cumulative distribution graphs for calculated parameters are obtained for these surfaces.

The process is repeated for different activities taking place in the Kocatepe Mosque. First reverberation time is measured in the empty mosque. The first activity mode is the prayer mode; for this, the source is the imam at the mihrab facing towards the mihrab set at a height of $0.80 \mathrm{~m}$. For daily prayers, the mosque is assumed one third full. The second mode is the preaching mode and recital of the musical versions of the Holy Quran. The source is the imam at the minbar facing the worshippers. The mosque is assumed full for Friday prayers, for listening to the Friday Speech, for religious days and festivals. The receiver surfaces for both activity modes are set at a height of $0.80 \mathrm{~m}$, approximately seating level. For the two different activity modes, music and speech related parameters are analyzed; these include reverberation time (RT), early decay time (EDT), clarity (C50), definition (D80), speech transmission index (STI), lateral fraction (LF) and strength $(\mathrm{G})$.

\section{Acoustical Analysis}

\section{Reverberation Time (RT)}

Reverberation time is the time required for a sound in a room to decay by $60 \mathrm{~dB}$ after the sound source has stopped. RT is the basic parameter that should be calculated in the assessment of room acoustics. RT characterizes the decay of sound for specifying the efficiency of a room in fulfilling the acoustical requirements depending upon the activity or function that takes place. For liturgical purposes (orchestra, chorus, or organ), the optimum range for reverberation time is 3.0 to $3.5 \mathrm{~s}$ for spaces larger than $10,000 \mathrm{~m}^{3}$ (Egan, 1994).

In the mosque, $\mathrm{RT}_{\text {unocc }}$ is $7.48 \mathrm{~s}$ in the middle frequencies. This is much longer than the optimum level even for liturgical purposes. Long sound decay at low frequencies can reduce the intelligibility of speech. For good intelligibility, RT values at low octave-band frequencies should remain flat down to $100 \mathrm{~Hz}$. At low frequencies, an increase in RT values of around 10\%-20\% would still yield a natural sound but in the case of Kocatepe, the increase is about $50 \%$ in the empty mosque. The bass ratio, which is the average RT at low to mid frequencies, is 1.54 in the Kocatepe Mosque, whereas the optimum range for music performances is 1.2 to 1.25 (Kuttruff, 1991). This value implies an over-warm space rich in bass sound; this is effective for spatial impression but detrimental to speech intelligibility.

Table 1: Sound absorption coefficients of different materials used in the Kocatepe Mosque.

\begin{tabular}{|l|c|c|c|c|c|c|c|c|c|}
\hline Material & $\mathbf{6 3}$ & $\mathbf{1 2 5}$ & $\mathbf{2 5 0}$ & $\mathbf{5 0 0}$ & $\mathbf{1}$ & $\mathbf{2}$ \\
$\mathbf{H z}$ & $\mathbf{H z}$ & $\mathbf{H z}$ & $\mathbf{H z}$ & $\mathbf{k H z}$ & $\begin{array}{c}\mathbf{8} \\
\mathbf{k H z}\end{array}$ & $\begin{array}{c}\text { Scattering } \\
\mathbf{F a c t o r}\end{array}$ \\
\hline Smooth concrete & 0.01 & 0.01 & 0.01 & 0.02 & 0.02 & 0.02 & 0.05 & 0.05 & 0,1 \\
\hline Marble & 0.01 & 0.01 & 0.01 & 0.01 & 0.01 & 0.02 & 0.02 & 0.02 & 0,2 \\
\hline Solid wood panel & 0.15 & 0.15 & 0.10 & 0.06 & 0.08 & 0.10 & 0.05 & 0.05 & 0,1 \\
\hline Double glazing & 0.02 & 0.02 & 0.06 & 0.03 & 0.03 & 0.02 & 0.02 & 0.02 & 0,1 \\
\hline Solid wooden door & 0.14 & 0.14 & 0.10 & 0.06 & 0.08 & 0.10 & 0.10 & 0.10 & 0,1 \\
\hline Prayers-1/1 per $\mathbf{~ m}^{\mathbf{2}}$ & 0.55 & 0.55 & 0.86 & 0.83 & 0.87 & 0.90 & 0.87 & 0.87 & 0,5 \\
\hline Prayers-1/3 per $\mathbf{~ m}^{\mathbf{2}}$ & 0.10 & 0.10 & 0.21 & 0.41 & 0.65 & 0.75 & 0.71 & 0.71 & 0,5 \\
\hline Ceramic tiles & 0.01 & 0.01 & 0.01 & 0.01 & 0.02 & 0.02 & 0.02 & 0.02 & 0,3 \\
\hline Carpet on concrete & 0.02 & 0.02 & 0.06 & 0.14 & 0.37 & 0.60 & 0.65 & 0.65 & 0,1 \\
\hline Chandelier & 0.35 & 0.35 & 0.25 & 0.18 & 0.12 & 0.07 & 0.04 & 0.04 & 0,2 \\
\hline Lime plaster & 0.04 & 0.04 & 0.05 & 0.04 & 0.08 & 0.04 & 0.06 & 0.06 & 0,1 \\
\hline
\end{tabular}




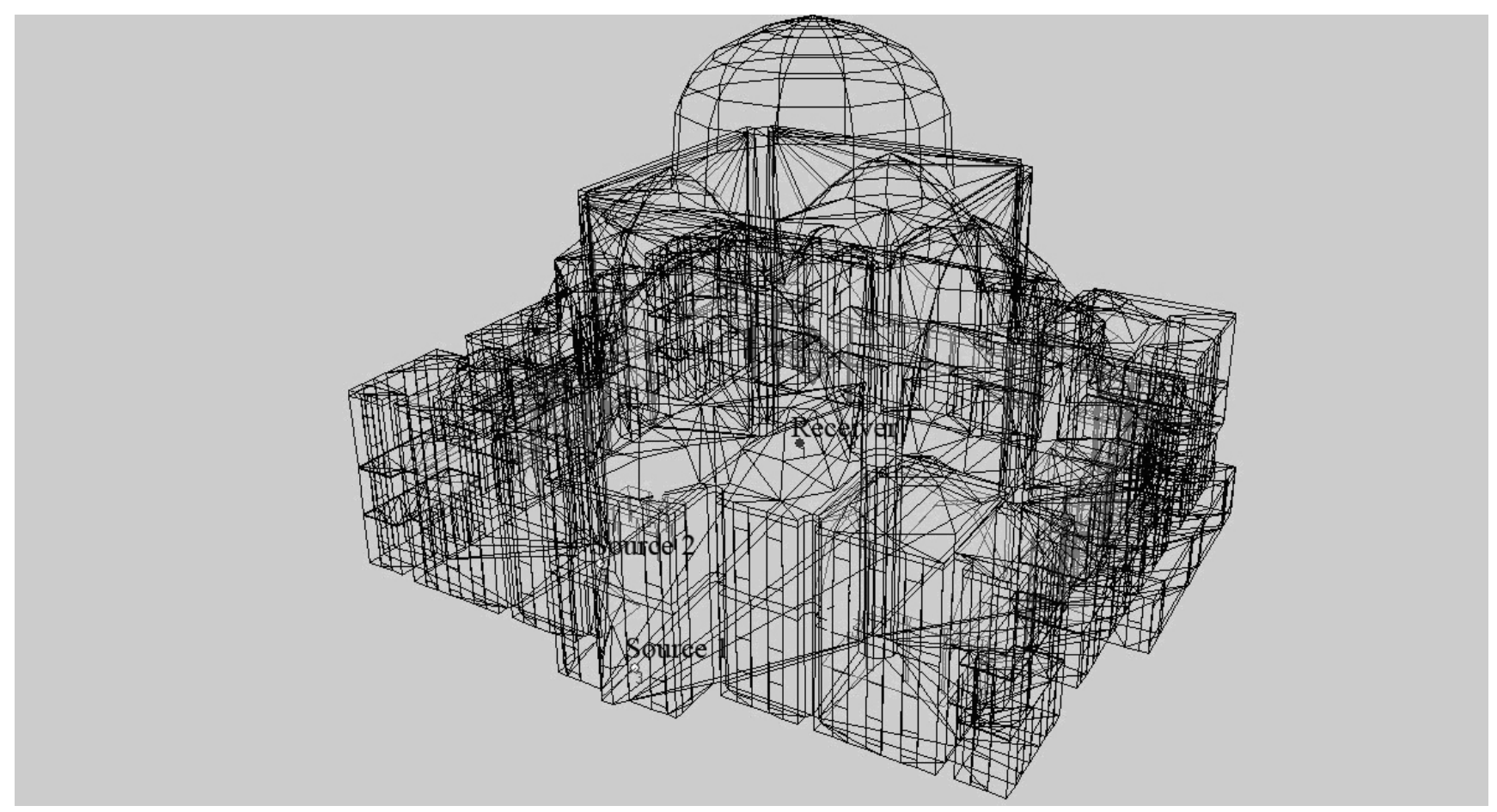

Figure 4: $3 D$ view of the source and receiver locations.

For the first activity mode, the prayer mode in a one third full mosque, the global estimation results show that the mosque has an $\mathrm{RT}_{1 / 3 \text { occ }}$ of $4.35 \mathrm{~s}$. at the mid frequencies. For the second activity mode, the preacher-recital mode in a full mosque, $\mathrm{RT}_{3 / 3 \mathrm{occ}}$ is $3.19 \mathrm{~s}$ at the mid frequencies (Figure 5). Distribution maps illustrate that $90 \%$ of the receiver surfaces has an $\mathrm{RT}_{1 / 3 \text { occ }}$ of $6.2 \mathrm{~s}$ and $\mathrm{RT}_{3 / 3 \text { occ }} 2.81$ to $3.89 \mathrm{~s}$ (see Appendix M1).

$\mathrm{RT}_{1 / 3 \text { occ }}$ is much better than $\mathrm{RT}_{\text {unocc }}$ but it is still higher than the optimum range. Any value greater than $1.0 \mathrm{~s}$ is especially detrimental to the intelligibility of speech (Kuttruff, 1991). The values obtained are unsatisfactory for both music and speech. A positive point worth mentioning is that the sound field is nearly even. There are a few echo spots underneath the dome but this is acceptable given the dimensions of the dome. $\mathrm{RT}_{3 / 3 \mathrm{occ}}$ is in the optimum range during the recitals of the musical version of the Holy Quran but in the preaching mode, it reduces the intelligibility of speech.

The number of worshippers attending Friday prayer greatly affects the total sound absorption inside the mosque and the duration reverberation time becomes more controlled. In these conditions, $\mathrm{RT}_{3 / 3 \text { occ }}$ is satisfactory for liturgical music underneath the main and secondary domes and there are almost no echo spots, despite the huge concave surface above. This results from the dimensions of the domes and their heights above the floor. When the main dome is completed to a sphere, it is far above the receiver surfaces. Therefore, none of the receiver surfaces is within this problematic focusing volume.

\section{Early Decay Time (EDT)}

EDT is roughly defined as the sensation of RT. It is a better indicator of the subjective feeling of reverberation time, and is critical in defining the acoustical quality of a music hall. The

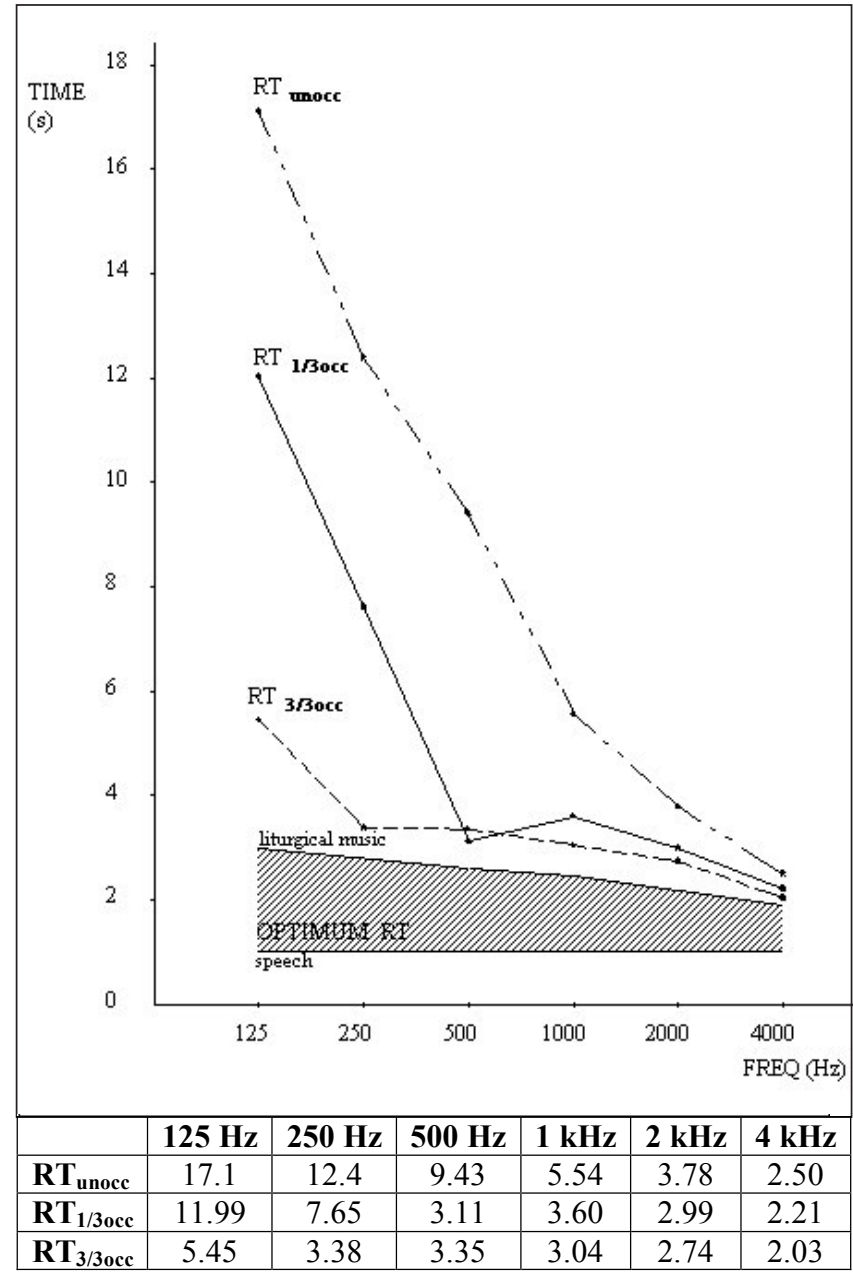

Figure 5: Calculated values for $R T_{\text {unocc }}$ and $R T_{1 / 30 c c}$ and $R T_{3 / 30 c c}$ for frequencies from 125 to $4000 \mathrm{~Hz}$, shaded area: optimum $R T$ (Egan 1994). 
EDT should not be higher than $\pm 10 \%$ for good acoustics. For liturgical purposes, EDT should be between 2.7 and 3.85 s (Templeton, 1993).

For the first activity (i.e. the $1 / 3$ full prayer mode), $\mathrm{EDT}_{1 / 3 \mathrm{occ}}$ is $6.3 \mathrm{~s}$ and for the second activity (i.e. the full preacher-recital mode), EDT $_{3 / 3 \text { occ }}$ is $4.4 \mathrm{~s}$ (see Appendix B. M2). Neither of these is in the optimum range. However, they are consistent with $\mathrm{RT}_{1 / 30 c \mathrm{cc}}$ and $\mathrm{RT}_{3 / 3 \text { occ }}$ implying a good distribution of sound throughout the mosque. Even though not as high scattering coefficients as to be expected are assigned to surfaces like column heads, stalactites, and ornamentation around mihrab, minbar and balconies within the simulation, considering their relatively small modeled size, there is still a proper amount of diffusion in the mosque that eliminates hot and dead spots and provides even distribution of sound especially in high frequencies. Using higher scattering coefficients for those small surfaces would probably be more accurate and cause much more drastic results and much of homogeneity of sound field.

\section{Clarity (C80)}

Clarity is defined technically as the ratio of early sound energy (arriving within $80 \mathrm{~ms}$ of direct sound) to late or reverberant sound energy (arriving more than $80 \mathrm{~ms}$ after the direct sound). This quality characterizes the separation in time of sounds from individual instruments or groups of instruments. This parameter must be within certain limits if the musical details are to be heard. In general, a satisfactory acoustical space should have clarity between -2 and $+2 \mathrm{~dB}$ to satisfy both music and speech criteria, and between -1 and +3 dB for choral music (Kuttruff, 1991).

In the first activity mode, $\mathrm{C} 80_{1 / 30 c c}$ is between -4 and $+4 \mathrm{~dB}$; in the second activity mode, $\mathrm{C} 80_{3 / 3 \text { occ }}$ is at $+1.8 \mathrm{~dB}$ for $90 \%$ of the receiver points (see Appendix M3). C $80_{1 / 3 \text { occ }}$ values are within the acceptable range at most of the receiver locations closer to the mihrab and around the muezzin platform. The values obtained are suitable for both music and speech. This indicates an adequate distribution of early reflections in these receiver locations. Values begin to decrease under the parts of the main dome that are closer to the sidewalls.

\section{Definition (D50)}

Definition is the measure derived from the ear's response to consecutive impulses; it characterizes the ratio of effective energy to the total energy in an impulse response up to $50 \mathrm{~ms}$. There is a good relationship between definition and speech intelligibility. This parameter should be greater than $20 \%$ to satisfy both music and speech performances (Templeton, 1993).

Table 2: Relation between scores of speech transmission quality and STI (RASTI).

\begin{tabular}{|l|c|}
\hline Quality Score & STI (RASTI) value \\
\hline Bad & 0 to 0.32 \\
\hline Poor & $0.32-0.45$ \\
\hline Fair & $0.45-0.60$ \\
\hline Good & $0.60-0.75$ \\
\hline Excellent & 0.75 to 1.0 \\
\hline
\end{tabular}

In the first activity mode, $\mathrm{D} 50_{1 / 3 \text { occ }}$ is above $30 \%$; in the second activity mode D50 $3 / 3$ occ varies between $22 \%$ and $50 \%$ (see Appendix M4).'D50 $1 / 3$ occ and $\mathrm{D} 50_{3 / 3 \text { occ }}$ are acceptable underneath the half of the main dome that is closer to the mihrab. Even surfaces underneath the secondary domes exhibit good values. This is probably caused by the first reflections off the domes and diffused surfaces of the stalactites between the columns and domes. The domes define an acoustical space underneath.

\section{Lateral Fraction (LF)}

Lateral fraction defines the relationship between a sense of spatial impression and the arrival of reflected sound from walls to the side of the listener (Templeton, 1993). For music, the parameter should be between $0.1-0.35$ and greater than 0.35 for all other purposes (Barron, 1993).

Both for the first and second activity modes, the $\mathrm{LF}_{1 / 3 \text { occ }}$ and $\mathrm{LF}_{3 / 3 \mathrm{occ}}$ values are above 0.30 (see Appendix B. M5). Better values are expected at points closer to the wall surfaces. The worst place in terms of $\mathrm{LF}_{1 / 3 \text { occ }}$ and $\mathrm{LF}_{3 / 3 \text { occ }}$ is underneath the main dome. $\mathrm{LF}_{3 / 30 c c}$ is better near the sidewalls, and around the muezzin platform.

\section{Speech Transmission Index (STI)}

STI is directly related to speech. To ensure good speech intelligibility, the envelope of the signal should be preserved, allowing the various frequency bands to contribute to speech quality. The scale of optimum values for the sound transmission index is shown in Table 2.

For the first activity mode, $\mathrm{STI}_{1 / 30 c c}$ is around 0.52 , which is considered fair; for the second activity mode, $\mathrm{STI}_{3 / 3 \text { occ }}$ is around 0.60, which is considered a good class (see Appendix M6). The results show that there is an even distribution of STI $\mathrm{S}_{1 / 3 \mathrm{occ}}$ throughout the mosque. At locations just around the source or imam, better values are seen. Enclosed buildings of large volume are not designed for optimal speech communication, so these results are satisfactory considering the volume of the mosque, $\mathrm{STI}_{3 / 3 \text { occ }}$ results are even better, indicating that the intelligibility of the imam at the minbar is satisfactory when the mosque is full.

The optimum volume per person for the intelligibility of the speech is between 4-6 $\mathrm{m}^{3}$ (Maekawa \& Lord, 1994). When the Kocatepe Mosque is considered full, the volume per person corresponds to $4.5 \mathrm{~m}^{3}$. Thus, the volume of the mosque meets acoustical requirements.

\section{Strength (G)}

Sound pressure level (SPL) maps indicate the $\mathrm{G}$ results, when an omni-directional source type and a power of $31 \mathrm{~dB} /$ Octave bands are selected from the appropriate Point Source Editor of ODEON software. For symphonic and liturgical music, G values should be greater than $3 \mathrm{~dB}$ (Lynge, 2001).

The simulation results for the first and second activity modes show that sound distribution is satisfactory underneath the main dome and even under the smaller domes (see Appendix M7). These smaller domes are effective in distributing the sound from the imam to further spots. $G_{3 / 30 c c}$ values are higher closer to the minbar than in the rest of the mosque; this is given that the imam is the source. 


\section{Conclusion}

Two important criteria in mosque acoustics are an even distribution of sound and optimum reverberation times. When all the parameters studied are considered, the results show that the Kocatepe Mosque is a good place for reciting the musical version of the Holy Quran, as it creates a ritual and tranquil acoustical atmosphere. However, for the prayer mode, the mosque has inadequate intelligibility of speech. This is verified by the abrupt jumps in reverberation time at low frequencies in the activity modes and when the mosque is empty. There is excessive reverberation and a high bass ratio in the empty mosque. However, a flat distribution of reverberation on frequency is important for intelligibility of speech, regardless of volume; sound absorption should be balanced for different frequencies. Ancient mosques achieved this bass balance by special acoustical treatments such as cavity resonators (Kayili, 2005)

Excessive reverberation may arise when the walls and the ceiling of an auditorium are covered with highly reflective material that causes a degradation of speech sounds, especially when the surface is concave. The sound reinforcement system would increase the direct sound level at listening positions and yield better intelligibility.

In the second activity mode, the number of worshippers attending Friday prayer greatly affects total sound absorption inside the mosque and the parameters fall within the desirable ranges. The mosque is successful in terms of sound focusing considering all of the activity patterns. In many new mosques, "focusing" is a serious problem, but in Kocatepe, this acoustical defect is overcome by the proportions and locations of the domes (Prodi \& Marsilio, 2003; Utami, 2005). As the main dome is above the receiver surfaces, none of the worshippers stay in the probable focusing volume. Secondary domes have no focusing effect; on the contrary, they provide sound energy to distant parts of the mosque and they provide a diffused field beneath them.

The ancient Mosques of Sinan are still unique and may be a reference and model for mosques yet to be built (CAHRISMA, 2007; Kayili, 2005; Topaktas, 2003). Except for cavity resonators, the basic architectural features of Kocatepe are inspired by some of the Sinan Mosques. The interior treatment of the mosque is important in providing a divine environment. The stalactites as a transitional architectural element between dome and columns, the ornamentation on the mihrab, the minbar, the columns and balconies-- all have not just aesthetic appeal, but also acoustical purposes especially in high frequencies.

It is clearly observed from the results that new era mosques with concrete domes have a greater tendency to keep and enhance the low frequency sounds within the audience area. This low frequency interferes with the speech intelligibility and puts constraints on the clarity of the lecture or the orders conveyed by the Imam. The materials used in ancient mosques, and the cavity resonator technique, with various sized glass pots within the dome, were wise and efficient in providing good acoustical quality. Recently developed acoustical devices such as Helmholtz resonators provide new design opportunities; these could duplicate the principle design criteria of Sinan, and could improve the acoustics of future mosques as well as Kocatepe.
However considering the feasibility of Helmholtz resonators within big spaces such as mosques, the authors would like to introduce micro-perforated panel absorbers to be studied more comprehensively in future applications and studies of mosque acoustics. This new technology uses the same physics principals as Helmholtz resonators in substantial attenuation of low frequencies, while keeping the high frequencies in the desired ranges. The architectural approach and feeling of the spaces could then be combined with the new technological improvements of this era, and architectural acoustics as a science could be greatly furthered.

In this study, the drawbacks of new construction techniques on the acoustics of contemporary mosques have been analyzed. The Kocatepe Mosque is one of the leading examples of the Ottoman style reinforced concrete dome typology in mosque acoustics and architecture. The acoustic simulations demonstrated that this mosque typology has strong aesthetic features but moderate acoustical effects in comparison to the authentic Ottoman mosques. The excessive reverberation in the low frequency range of the energy decay is found to be the basic problem of that new typology. The key to improve the problems in today's mosques is to adjust and combine the material technology of the era to the aesthetics of ancient mosques such that it fits to the concept, and eventually to the functionality of the mosques acoustics.

\section{References}

Abdou, A.A. (2003). Measurement of acoustical characteristics of mosques in Saudi Arabia, The Journal of Acoustical Society of America, 113(3), 1505-1517.

Barron, M. (1993). Auditorium Acoustics and Architectural Design. London: E \& FN Spon.

CAHRISMA, (2007). Orsted-DTU. Available at http://server.oersted. dtu.dk/www/oldat/cahrisma, retrieved 4 September 2007.

Egan, M.D. (1994). Architectural Acoustics. New York: McGraw-Hill.

Fausti, P., Pompoli, R., \& Prodi, N. (2003). Comparing the acoustics of mosques and Byzantine churches. $19^{\text {th }}$ International Symposium CIPA (The International Committee for ArchitecturalPhotogrammetry). Antalya, Turkey: Technical University of Istanbul.

Hamadah, H.A., \& Hamouda, H.M. (1998). Assessment of speech intelligibility in large auditoria case study: Kuwait State Mosque. Applied Acoustics, 54(4), 273-289.

Karabiber, Z. (1999). Acoustical problems in mosques: A case study on the three mosques in Istanbul. Forum Acusticum, Berlin, CDROM, 4 pgs.

Karabiber, Z. (2000). A new approach to an ancient subject: CAHRISMA project. In Proceedings of the $7^{\text {th }}$ International Congress on Sound and Vibration (1661-1668). Garmisch-Partekirchen, Germany: International Institute of Acoustics and Vibration.

Karabiber, Z., \& Erdogan, S. (2002). Comparison of the acoustical properties of an ancient and a recent mosque. Forum Acusticum, Seville, Spain: Spanish Acoustical Society (SEA). Available at http://www.cica.es/-forum2002, retrieved 4 September 2007.

Kayili, M. (2000). Use of cavity resonators in Anatolia since Vitruvius. International Institute of Acoustics and Vibration, 3, 1621-1628.

Kayili, M. (2002). Anadolu' da geleneksel akustik sistemler ve Mimar Sinan uygulamaları (Anatolian traditional acoustic works and works done by Sinan the Architect) [Turkish], In Proceeding of $6^{\text {th }}$ National Acoustical Congress TAKDER, 26-28 October (233-238). Antalya, Turkey: Turkish Acoustical Society. 
Kayili, M. (2005). Acoustic Solutions in Classic Ottoman Architecture. Manchester, England: Foundation for Science Technology and Civilization; also available at http://www.fstc.co.uk, retrieved 4 September 2007.

Kuttruff, H. (1991). Room Acoustics. London: Elsevier.

Lynge, C. (2001). ODEON Room Acoustics Program Version 5.0 User Manual: Industrial, Auditorium and Combined Editions. Lyngby, Denmark: Orsteds Plads.

Maekawa, Z., \& Lord, P. (1994). Environmental and Architectural Acoustics. London: E\&FN Spon.

Naylor, G.M. (1993). ODEON: Another hybrid room acoustical model. Applied Acoustics, 38, 131-143.

Prodi, N., \& Marsilio, M. (2003). On the effect of domed ceiling in worship spaces: A scale model study of a mosque. Building Acoustics, 10(2), 117-133.

Rindel, J.H. (2000). The use of computer modeling in room acoustics. Journal of Vibroengineering, 3, 219-224.

Schmidt, A.M.D., \& Kirkegaard, P.L. (2004). On architectural acoustics design using computer simulation. In Eleventh International Congress on Sound and Vibration. St Petersburg, Russia: International Institute of Acoustics and Vibration (IIAV).

Steeneken, H.J.M., \& Houtgast, T. (1980). A physical method for measuring speech-transmission quality. Journal of the Acoustical Society of America, 67(1), 318-326.

Suarez, R., Sendra, J.J., Navarro, J., \& Leon, A.L (2004). The acoustics of the cathedral mosque of Cordoba: Proposals for architectural intervention. Acta Acustica United with Acustica, 90, 362-375.
Templeton, D. (1993). Acoustics in the Built Environment: Advice for the Design Team. Oxford: Butterworth.

Topaktas, I.L. (2003). Acoustical properties of classical Ottoman mosques: Simulation and measurements. Unpublished $\mathrm{PhD}$ thesis, Department of Architecture, Middle East Technical University, Ankara.

Türkiye Diyanet Vakfi (Presidency of Religious Affairs) (2007). Kocatepe Mosque. http://www.diyanetvakfi.org.tr/eserler/ kocatepecamii/kocatepe_camii.pdf, retrieved 4 September 2007.

Utami, S.S. (2005). An acoustical analysis of domes coupled to rooms, with special application to the Darusshol Mosque. Unpublished M.S. thesis, Brigham Young University, Salt Lake City, USA. .

Weitze, C.A, Christensen, C.L., Rindel, J.H., \& Gade A.C. (2001). Computer simulations of the acoustics of mosques and Byzantine churches. In $17^{\text {th }}$ International Congress on Acoustics. Rome: Italian Acoustical Society.

Yuksel, Z.K., Binan, C., \& Unver, R. (2003). A research project in the intersection of architectural conservation and virtual reality: CAHRISMA. In $19^{\text {th }}$ International Symposium CIPA (The International Committee for Architectural Photogrammetry. Antalya, Turkey: Technical University of Istanbul.

\section{Appendix}

Calculated parameter distribution maps for different activity patterns:

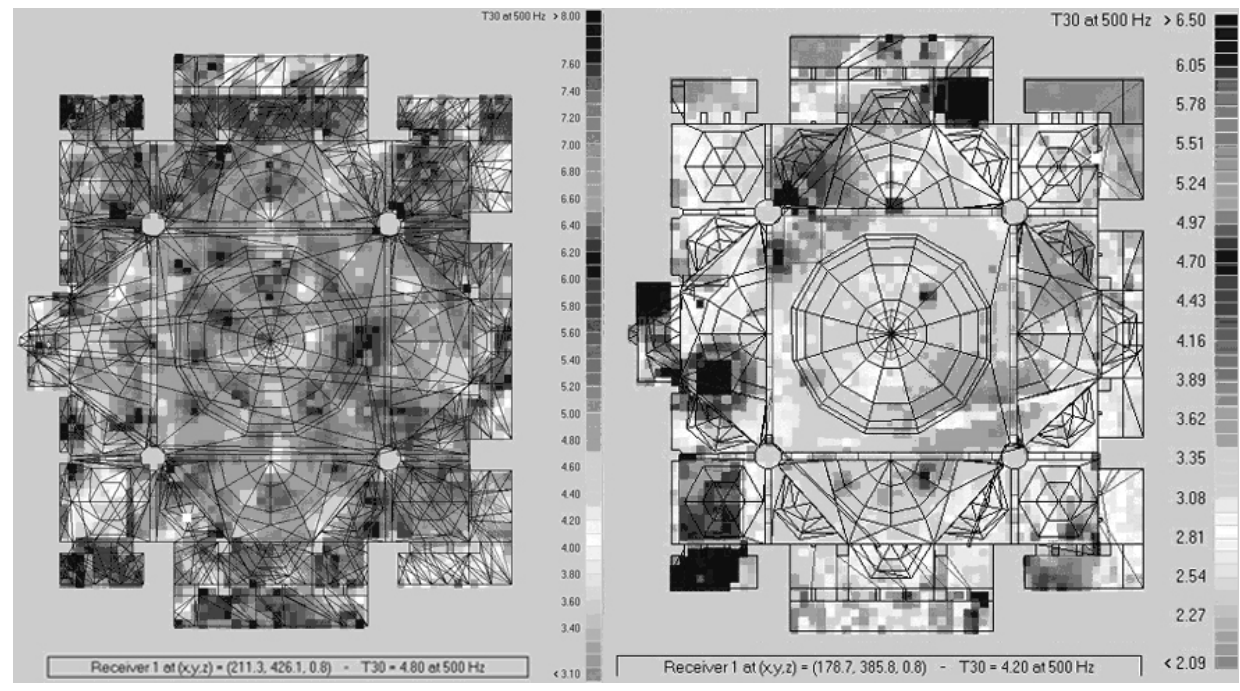

M1: a) Reverberation time distribution maps for $500 \mathrm{~Hz}$ source at mihrab,

b) Reverberation time distribution maps for $500 \mathrm{~Hz}$ source at minbar. 


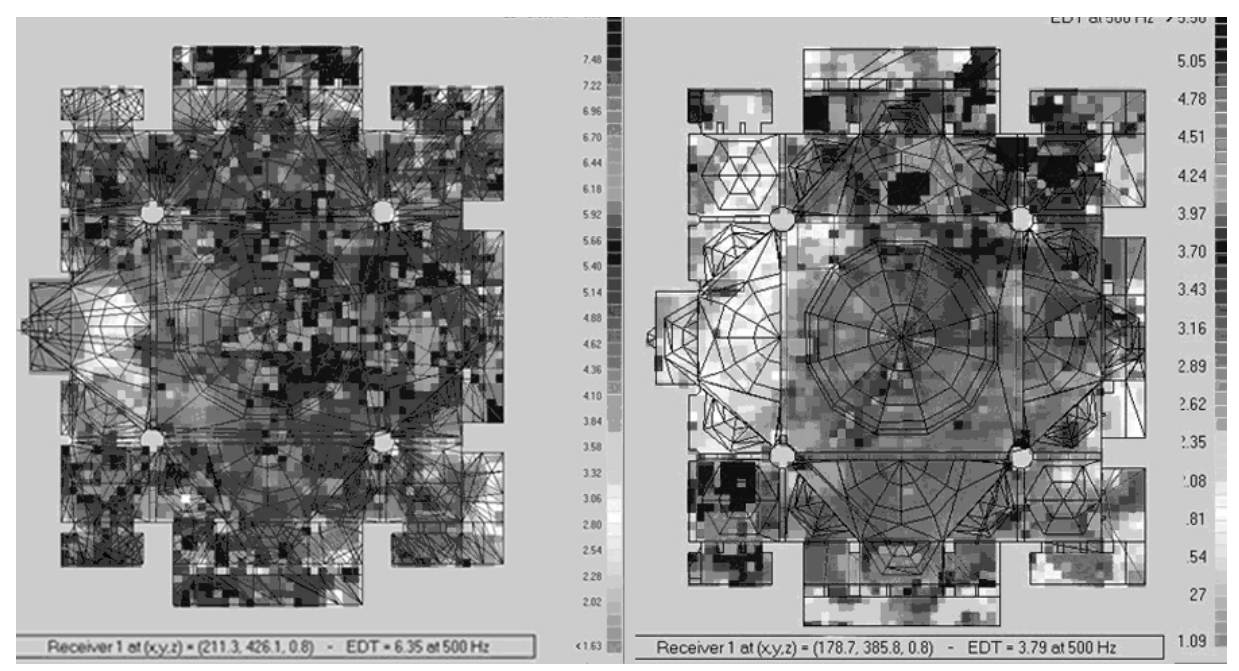

M2: a) Early decay time distribution maps for $500 \mathrm{~Hz}$ source at mihrab,

b) Early decay time distribution maps for $500 \mathrm{~Hz}$ source at minbar.

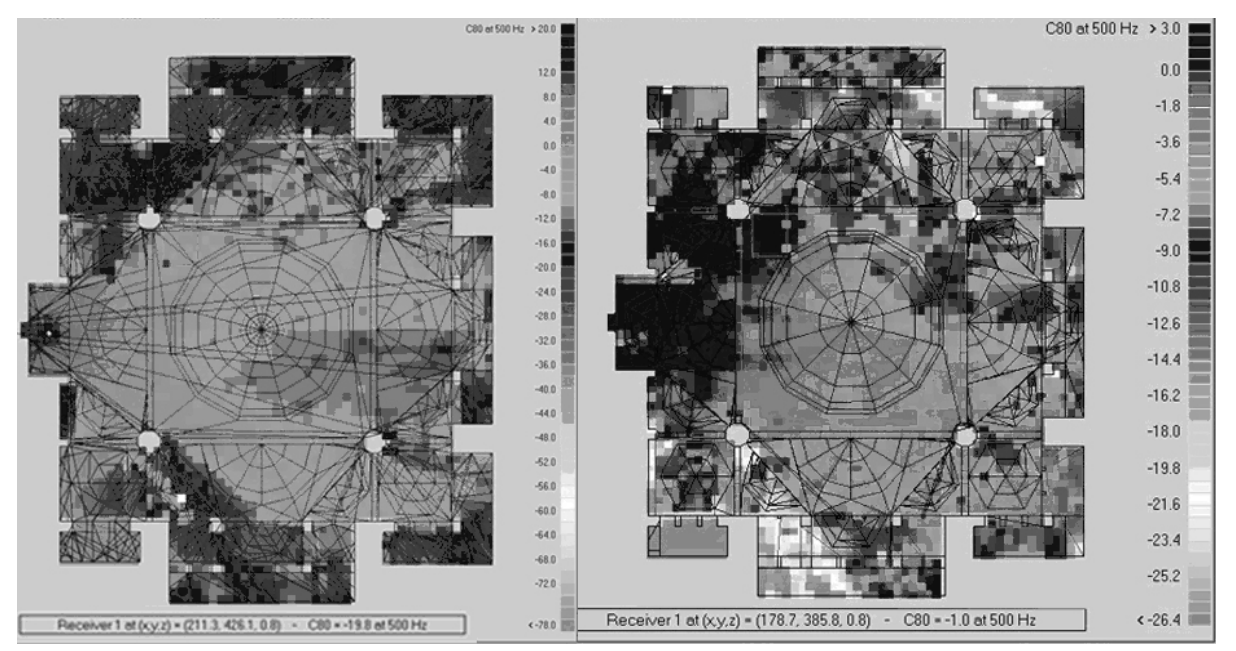

M3: a) Clarity distribution map for $500 \mathrm{~Hz}$, source at mihrab,

b) Clarity distribution map for $500 \mathrm{~Hz}$, source at minbar.

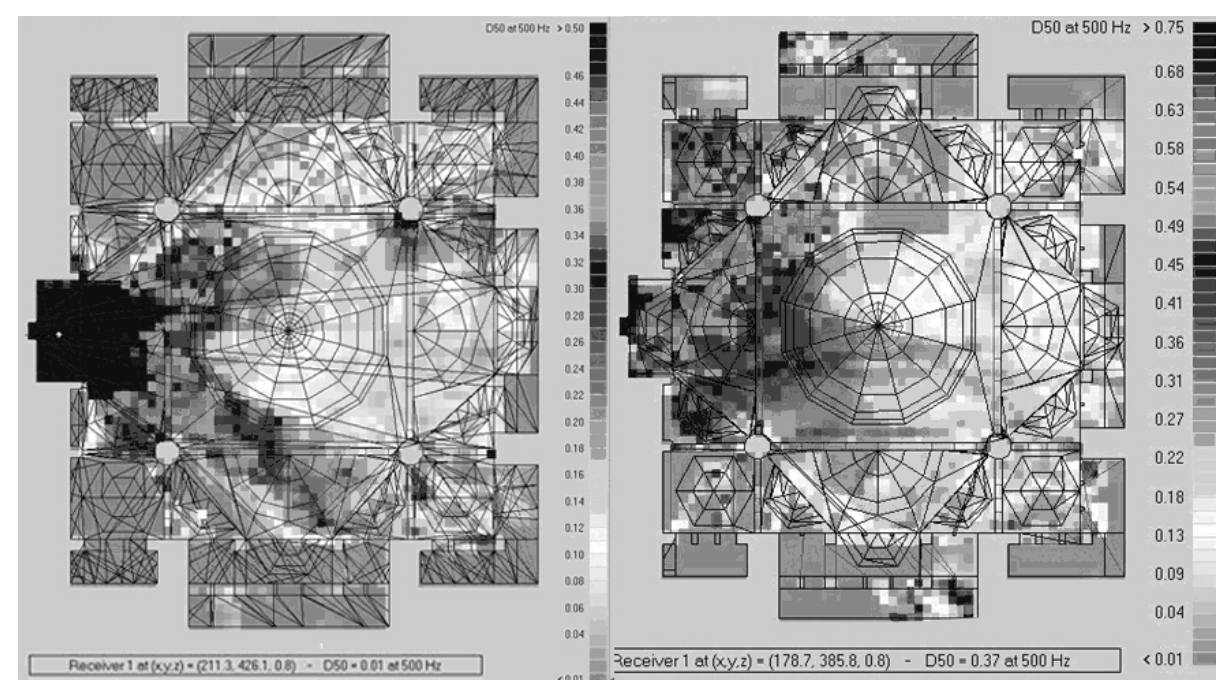

M4: a) Definition distribution map for $500 \mathrm{~Hz}$, source at mihrab, b) Definition distribution map for $500 \mathrm{~Hz}$, source at minban. 


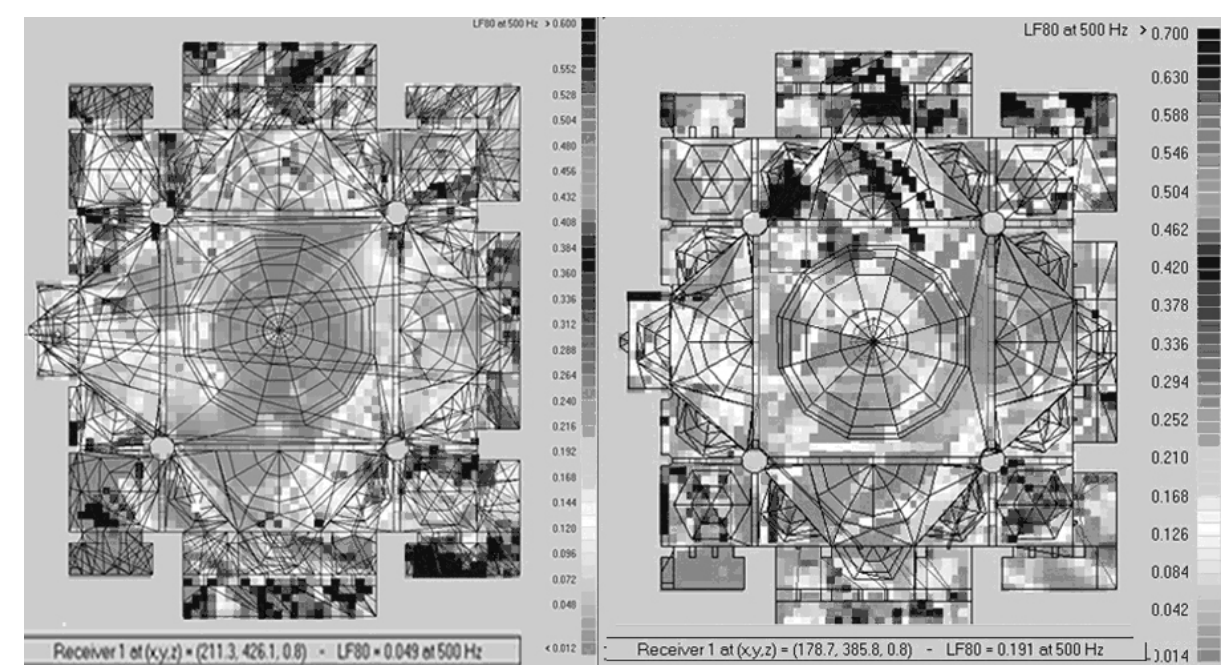

M5: a) Lateral fraction distribution map for $500 \mathrm{~Hz}$, source at mihrab,

b) Lateral fraction distribution map for $500 \mathrm{~Hz}$, source at minbar.

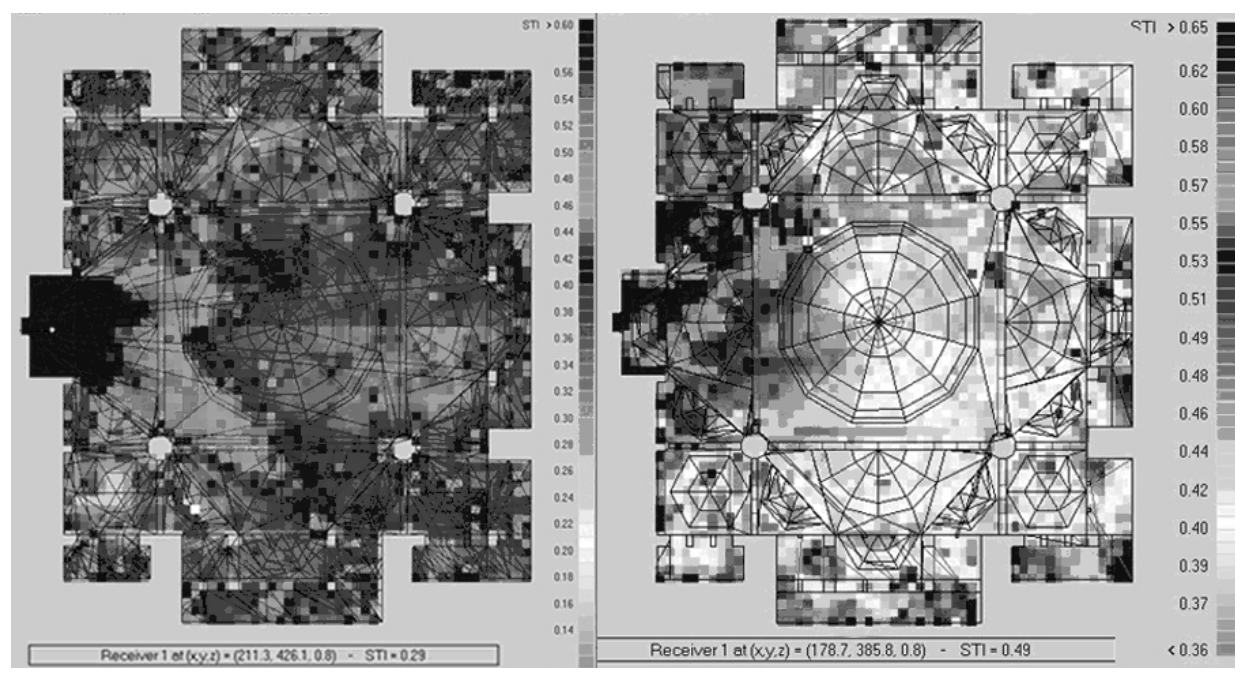

M6: a) Speech transmission index distribution map, source at mihrab,

b) Speech transmission index distribution map, source at minbar.

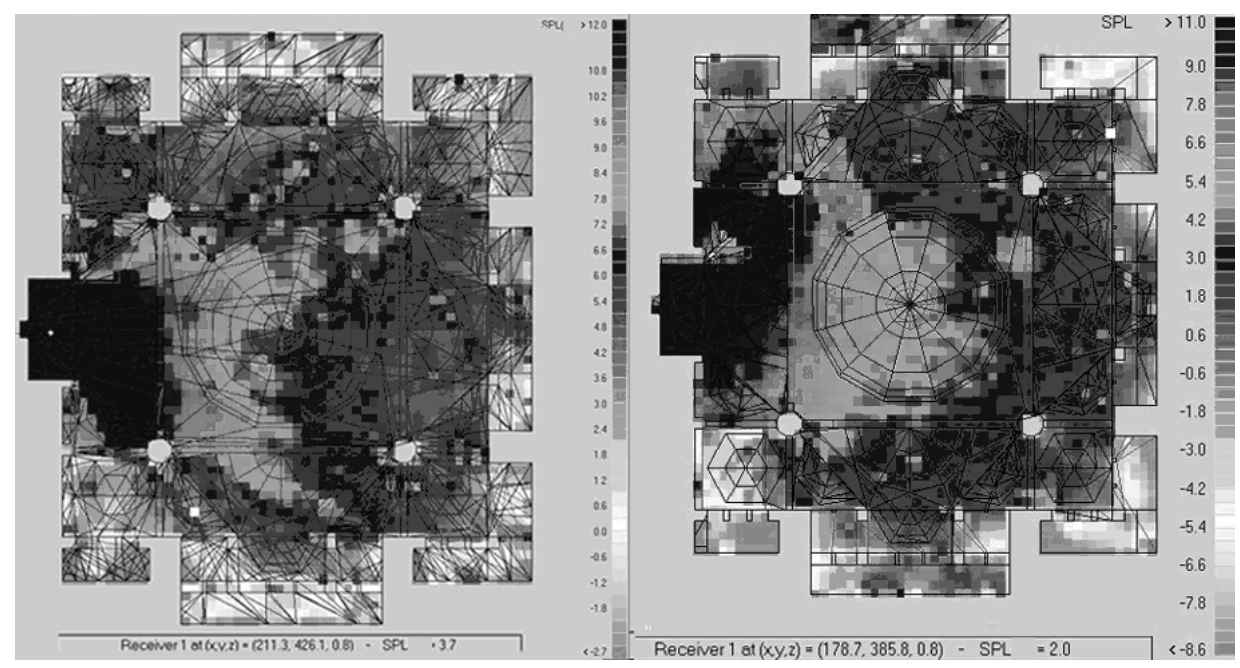

M7: a) Strength distribution map, source at mihrab,

b) Strength distribution map, source at mihrab. 